\title{
Monitoramento de uma unidade de beneficiamento de sementes de milho
}

\author{
Fabiana Schmidt
}

\begin{abstract}
Resumo - O objetivo desse trabalho foi avaliar o beneficiamento de sementes de milho de variedades VPA, identificar falhas e limitantes técnicos operacionais na Unidade de Beneficiamento de Sementes de Milho (UBS). Foram acompanhadas as etapas de colheita, seleção de espigas, secagem, limpeza, classificação, ensacamento e armazenagem da semente. A empresa é rigorosa no processo de produção de sementes, dispondo de um produto com alta qualidade, pois os lotes beneficiados apresentaram pureza de 100\%, germinação entre $90-99 \%$ e percentual de sementes infestadas inferior a três. Os processos executados na UBS foram eficientes na eliminação de materiais indesejáveis e na preservação da integridade física das sementes. Como melhorias necessárias aponta-se o aumento da produtividade e qualidade sanitária das sementes colhidas nos campos de produção, substituição da despalha manual por mecânica, introdução de mostruário na seleção de espigas, adoção do teste de peneiras nas etapas de classificação para garantir uniformidade dos lotes beneficiados.
\end{abstract}

Termos para indexação: Zea mays; lote de sementes; qualidade das sementes.

\section{Monitoring of a maize Seed Processing Unit}

Abstract - The objective of this work was to evaluate the processing open pollinated varieties corn seeds, to identify faults and technical limitations at the corn seed Processing Unit (SPU). The process of drying, cleaning, sorting, bagging and storage of the seed were monitored. The company follows strict regulations in the processing seed, providing a product with high quality because the beneficiated lots presented a purity of $100 \%$, germination between $90-99 \%$, and percentage of infested seeds less than three. The processes performed in the SPU were efficient in the cleaning undesirable products and preservation the physical integrity of the seeds. It were pointed out the need to increase the productivity and sanitary quality in the seeds production fields, the substitution of manual threshing by mechanics, the introduction of standard display for the standard ears corn selection, and the adoption of sieves test in the classification phases to ensure physical uniformity of the lots benefited.

Index terms: Zea mays L.; seed lot; seed quality.

A utilização de sementes de alta qualidade por parte dos agricultores é fundamental para o êxito no estabelecimento da cultura do milho a campo, pois determina a porcentagem de emergência, o estande e a uniformidade da distribuição de plantas na área, sendo estes requisitos para a obtenção de elevadas produtividades. A obtenção de sementes de qualidade implica a adoção de práticas adequadas à produção de sementes que começam no campo e se consolidam após o beneficiamento. Nos campos de produção de sementes os cuidados devem iniciar na escolha da área e da época de plantio, operações de semeadura, tratos culturais, manejo de plantas invasoras e colheita (MARTIN et al., 2007).

O beneficiamento de sementes é a etapa que visa melhorar as características boas (qualidade física e fisiológica) de um lote através da uniformização da semente destinada à comercialização e da eliminação das impurezas (CARVALHO \& NAKAGAWA, 2000). A semente de milho normalmente é colhida, despalhada e secada na espiga, para após ser debulhada, limpa e classificada (FERREIRA \& SÁ, 2010). A espiga de miIho apresenta variações de forma e tamanho das sementes, assim, a classificação é necessária para a uniformização das sementes.

Nas etapas do beneficiamento, o milho é conduzido por diversas máquinas de processamento com o objetivo principal de melhorar a qualidade física e fisiológica do lote, que possibilita enquadramento em padrões qualitativos preestabelecidos. A sequência de equipamentos utilizada no beneficiamento, a regulagem e a limpeza dos mesmos, são indispensáveis para obtenção de sementes de alta qualidade. O acompanhamento das sementes após a colheita em todas etapas do beneficiamento possibilita a identificação dos pontos críticos da produção e a rápida solução de eventuais problemas que venham reduzir a qualidade das sementes. Assim, é possível identificar o local exato onde está ocorrendo o problema e solucionálo, disponibilizando sementes de meIhor qualidade para o produtor (TROGELLO et al., 2013).

No presente estudo de caso, objetivou-se acompanhar as etapas do beneficiamento de sementes de milho de três variedades de polinização aberta

Recebido em 4/2/2019. Aceito para publicação em 25/4/19.

${ }^{1}$ Engenheira-agrônoma(o), Dra., Epagri/Estação Experimental de Campos Novos, BR-282, Km 338,2 S/N, Bairro Boa Vista, 89620-000, Campos Novos, SC, fone:

(47)3541-3500, e-mail: fabianaschmidt@epagri.sc.gov.br. 
(VPA) e identificar possíveis falhas e limitantes técnicos operacionais na Unidade de Beneficiamento de Sementes de Milho (UBS) da Empresa de Pesquisa Agropecuária e de Extensão Rural de Santa Catarina (Epagri), na Estação Experimental de Campos Novos. A UBS acompanhada nesse estudo opera com o beneficiamento e a classificação de sementes certificadas de milho das variedades da Epagri SCS154 Fortuna, SCS155 Catarina e SCS156 Colorado. As sementes beneficiadas são oriundas de campos de produção registrados no Ministério da Agricultura, Pecuária e Abastecimento (Mapa), localizados nos municípios de Chapecó (SCS155 Catarina e SCS156 Colorado) e Campos Novos (SCS154 Fortuna), em Santa Catarina.

Na safra 2017/2018 foram recebidas para o beneficiamento 11,8 toneladas de milho em espiga com palha de SCS154 Fortuna; 48,4 toneladas de SCS155 Catarina e 13,4 toneladas de SCS156 Colorado. Foram beneficiados no total $31.260 \mathrm{~kg}$ de sementes de milho que foram acondicionadas em embalagens de papel Kraft multifoliado contendo $10 \mathrm{~kg}$ de sementes tratadas. Antes de ser realizada a colheita mecanizada, espigas de milho das três variedades foram coletadas manualmente no campo de produção para determinação da umidade da semente. As variedades de milho foram colhidas mecanicamente por colheitadeira com plataforma espigadeira com a umidade das sementes nas espigas de $27 \%$ (SCS 154 Fortuna) e 23\% (SCS 155 Catarina e SCS 156 Colorado), respectivamente.

$\mathrm{Na}$ recepção, após a chegada do caminhão na UBS, as espigas de milho foram despalhadas e selecionadas manualmente, sendo os percentuais médios de descarte das espigas colhidas no campo de produção os seguintes: $33 \%$ para SCS154 Fortuna, 35\% para SCS155 Catarina e 38\% para SCS 156 Colorado. $\mathrm{Na}$ seleção de espigas foram descartadas as espigas com grãos podres ou ardidos, espigas carunchadas, espigas de cor de sabugo diferente, além das espigas com tipos de grãos e colorações diferentes das espigas padrões das variedades selecionadas.

$\mathrm{Na}$ etapa da recepção foi verificada a necessidade de implementar altera- ções nos procedimentos operacionais, a primeira se refere à substituição da despalha manual das espigas pela despalha mecânica. A despalha manual torna o processo demorado e implica maior permanência das espigas na recepção (2 a 3 meses), o que facilita o ataque de insetos como o gorgulho do milho (Sitophilus zeamais). A segunda alteração a ser adotada se refere à utilização de um mostruário no momento da seleção das espigas indicando o que são espigas-padrão e o que deve ser eliminado.

Feita a seleção, as espigas foram encaminhadas para a moega com umidade de $22 \%$ (SCS154 Fortuna), 21\% (SCS155 Catarina) e $24 \%$ (SCS156 Colorado). A moega onde as espigas de milho foram depositadas foi devidamente limpa e livre de qualquer forma de contaminação, seja ela física, genética ou sanitária. A limpeza evita a mistura de sementes de variedades diferentes, minimiza a presença de sementes malformadas e a contaminação com estruturas veiculadoras de pragas e doenças, maximizando a pureza e a qualidade sanitária.

As espigas de milho foram conduzidas por esteiras e elevador da moega para um silo secador dividido em 10 compartimentos que possuem fundo falso perfurado.

$\mathrm{O}$ ar quente gerado pela queima da lenha foi injetado dentro do silo e misturado com o ar frio através de dois túneis principais para controle do fluxo de ar (fluxos ascendente e descendente). Para a secagem das espigas foi empregada a temperatura do ar de secagem de $40^{\circ} \mathrm{C}$ durante 72 a 90 horas até as sementes atingirem umidade entre 13 e $14 \%$.

Ao fim da secagem, as espigas foram debulhadas em um debulhador de molinete cilíndrico com dentes, sendo utilizada a rotação do debulhador ao redor de 400rpm. Em seguida, as sementes passaram pela máquina de pré-limpeza, onde as sementes foram separadas em três grupos: impurezas maiores que as sementes, as sementes e, por último, impurezas menores que as sementes. Após a pré-limpeza das sementes, iniciou-se a etapa de classificação. As sementes de milho foram classificadas quanto à sua forma (redonda ou achatada/lisa) e quanto aos seus diferentes tamanhos, buscando uniformizar o lote de sementes e facilitar a semeadura.

Na primeira etapa da classificação, as sementes passaram pela máquina constituída por um conjunto de três peneiras de furos oblongos que separa a semente quanto à forma. Em seguida, as sementes achatadas seguiram para classificação quanto ao tamanho e as sementes redondas permaneceram no reservatório sendo posteriormente classificadas. A classificação por tamanho foi realizada na máquina de ar e peneiras (MAP), que classificou as sementes achatadas/lisas em 4 distintos tamanhos: peneira $18(6 \mathrm{~mm})$, peneira $20(7 \mathrm{~mm})$, peneira $22(8 \mathrm{~mm})$ e peneira $24(9 \mathrm{~mm})$. Após classificação pelo tamanho, as sementes seguiram para o separador de cilindro alveolado (trieur), que separa as sementes quanto ao seu comprimento em curta, média e longa. Apenas as sementes lisas retidas nas peneiras $20(7 \mathrm{~mm})$ e $22(8 \mathrm{~mm})$, que representaram as maiores quantidades, foram classificadas no trieur. Na etapa posterior, as sementes seguiram para a mesa gravitacional, equipamento que separa pelo peso específico, onde as sementes mais leves, devido ao ataque de insetos e de microrganismos ou porque eram malformadas, foram totalmente removidas. Após a finalização da classificação das sementes lisas/achatadas, as máquinas foram limpas e receberam as sementes redondas que foram classificadas quanto ao tamanho pela MAP e seguiram para a mesa gravitacional.

$\mathrm{Na}$ etapa de classificação sugere-se a introdução do teste de retenção nas peneiras para avaliar o processo de classificação quanto a forma e tamanho após a passagem das sementes em cada máquina. Outro teste que pode ser adicionado ao controle de qualidade da classificação das sementes é o de plantabilidade, que deverá ser executado em todos os lotes recém-beneficiados, onde se determina o número de falhas e duplos. É comum as empresas adotarem como norma que as sementes sejam repassadas no processo de classificação quando o lote apresentar mais de $3 \%$ de falhas e $6 \%$ de duplos (TROGELLO et al., 2013). Esse teste também permite a recomendação do disco e do anel mais apropriado para a semeadura de 
cada lote beneficiado no campo.

Finalizada a classificação, as sementes seguiram para a etapa de tratamento químico. Para conservar a qualidade das sementes foi utilizado um fungicida sistêmico e de contato composto do ingrediente ativo Metalaxyl-M (acilalaninato) + Fludioxonil (fenilpirrol) na dosagem de $150 \mathrm{pc} 100 \mathrm{~kg}$ de sementes. $E$ inseticida de contato e ingestão do grupo químico dos piretroides, princípio ativo Deltametrina (K-Obiol ${ }^{\circledR} 25$ CE) na dosagem de $80 \mathrm{ml}$ por $1000 \mathrm{~kg}$ de sementes e Pirimifós-metílico 50\% (Actellic $500 \mathrm{EC}$ ) na dosagem de $30 \mathrm{~mL}$ por $1000 \mathrm{~kg}$ de sementes. O corante utilizado no tratamento foi o vermelho resin TLB na dosagem de $300 \mathrm{ml}$ por $1000 \mathrm{~kg}$ de sementes. Além disso, foram realizadas pulverizações com os produtos citados acima nas instalações do secador e armazém, aplicação de pastilhas do fumigante fosfina nas espigas acondicionadas no secador e no armazenamento das sementes e aplicações de iscas de raticidas no armazém para a inibição de animais roedores.

$O$ ensaque das sementes tratadas foi realizado em sacos de papel Kraft multifoliado, sendo a sacaria padronizada em $10 \mathrm{~kg}$ de sementes através de pesagem em balança. Cada saco foi adesivado com etiquetas que contêm o número do lote, a categoria da semente, o cultivar referente ao lote, a peneira de classificação, a safra correspondente, o percentual de germinação mínima e a pureza mínima. Quanto ao armazenamento, a semente ensacada foi alocada sobre pallets a fim de facilitar o manejo no posterior transporte e evitar o contato da sacaria com o piso do armazém. Cada lote foi armazenado separadamente, em condições de armazém com umidade relativa média do ar variando de 58 a $97 \%$ e temperatura média do ar de 5 a $20^{\circ} \mathrm{C}$ livre de insetos e roedores. $\mathrm{O}$ produto ficou armazenado por um período de 30 dias até no máximo 90 dias (junho a agosto).

$\mathrm{Na}$ safra 2018/19 foram obtidos $31.260 \mathrm{~kg}$ de sementes beneficiadas, o que representa um aproveitamento médio de $38 \%$ do milho espiga colhido (Tabela 1). A variedade SCS 156 Colorado apresentou o maior percentual de descarte no período analisado com aproveitamento médio de 35\%. O maior descarte nas etapas de recepção (seleção de espigas) e limpeza/classificação ocorreu devido ao ataque de gorgulhos nas espigas na recepção. As variedades SCS154 Fortuna e SCS155 Catarina apresentaram cerca de $39 \%$ de aproveitamento, descarte de 33 e $35 \%$ das espigas na recepção no processo de seleção, respectivamente, e descarte na UBS de cerca de $13,6 \%$ para ambas as variedades.

Os resultados indicam que o descarte de espigas na recepção está em patamares elevados, sendo necessário tomar medidas corretivas no campo de produção de sementes que permitam reduzir esses valores (Tabela 1). Os descartes na seleção de espigas ocorreram principalmente devido ao ataque de insetos e à incidência de doenças nas espigas (grãos ardidos) e ao número expressivo de espigas de tamanho pequeno. Dessa forma, as principais ações recomendadas são evitar o atraso da coIheita e não realizar secagem natural do milho na própria planta em condições de campo (Ug de $23 \%$ nas sementes de SCS155 Catarina e SCS156 Colorado no momento da colheita) para evitar a ex-

Tabela 1. Parâmetros técnicos da produção de milho semente na safra 2017/18

Table 1. Technical parameters of corn seed production in the 2017/18 harvest

\begin{tabular}{|c|c|c|c|c|}
\hline \multirow{2}{*}{ Parâmetros avaliados } & \multicolumn{4}{|c|}{ Variedades de milho VPA beneficiadas- Safra 2017/2018 } \\
\hline & SCS154 Fortuna & SCS155 Catarina & SCS156 Colorado & Total \\
\hline Área plantada (ha) & 2,80 & 6,57 & 2,00 & 11,37 \\
\hline Rendimento (kg ha-1) & 7.000 & 7.372 & 6.700 & \\
\hline Produção milho espiga (kg) & 19.600 & 48.435 & 13.400 & 81.435 \\
\hline Ug milho - colheita (\%) & 27 & 23 & 23 & \\
\hline Descarte de espigas (\%) & 33 & 35 & 38 & \\
\hline Palha (\%) & 5,5 & 7,4 & 6,1 & \\
\hline Ug milho - moega (\%) & 22 & 21 & 24 & \\
\hline Milho espiga na secagem (kg) & 11.656 & 28.279 & 7.813 & \\
\hline Ug milho saída do secador (\%) & 12 & 12 & 12 & \\
\hline Milho espiga na debulha (kg) & 10.365 & 25.556 & 6.780 & \\
\hline Sabugo (\%) & 14,7 & 14,5 & 14,1 & \\
\hline Milho grão - classificação (kg) & 8.840 & 21.840 & 5.823 & \\
\hline Descarte na UBS (\%) & 13,6 & 13,6 & 18,6 & \\
\hline Total sementes beneficiadas ( $\mathrm{kg}$ ) & 7.640 & 18.880 & 4.740 & 31.260 \\
\hline Embalagens (sc 10kg) & 764 & 1.888 & 474 & \\
\hline Aproveitamento (\%) & 39 & 39 & 35 & 38 \\
\hline
\end{tabular}


Tabela 2. Quantidade e germinação das sementes de milho de lotes beneficiados na safra 2017/18

Table 2. Quantity and germination of seeds corn from beneficiated lots in the harvest 2017/18

\begin{tabular}{lccccccccc}
\hline Peneira & \multicolumn{3}{c}{ Quantidade (kg) } & \multicolumn{3}{c}{ Percentual (\%) } & \multicolumn{3}{c}{ Germinação (\%) } \\
\cline { 2 - 10 } & $\begin{array}{l}\text { SCS154 } \\
\text { Fortuna }\end{array}$ & $\begin{array}{c}\text { SCS155 } \\
\text { Catarina }\end{array}$ & $\begin{array}{c}\text { SCS156 } \\
\text { Colorado }\end{array}$ & $\begin{array}{c}\text { SCS154 } \\
\text { Fortuna }\end{array}$ & $\begin{array}{c}\text { SCS155 } \\
\text { Catarina }\end{array}$ & $\begin{array}{c}\text { SCS156 } \\
\text { Colorado }\end{array}$ & $\begin{array}{c}\text { SCS154 } \\
\text { Fortuna }\end{array}$ & $\begin{array}{c}\text { SCS155 } \\
\text { Catarina }\end{array}$ & $\begin{array}{c}\text { SCS156 } \\
\text { Colorado }\end{array}$ \\
\hline P.20L & 410 & 500 & 340 & 5,4 & 2,6 & 7,2 & 95 & 93 & 97 \\
\hline P.20R & 220 & 290 & 250 & 2,9 & 1,5 & 5,3 & 96 & 90 & 95 \\
\hline P.22L & 2.330 & 5.000 & 1.930 & 30,5 & 26,5 & 40,7 & 98 & 95 & 96 \\
\hline P.22C & 290 & 660 & - & 3,8 & 3,5 & - & 90 & 91 & - \\
\hline P.22R & 1.570 & 2.890 & 1.380 & 20,5 & 15,3 & 29,1 & 96 & 90 & 95 \\
\hline P.24L & 1.020 & 2.300 & 180 & 13,3 & 12,2 & 3,8 & 97 & 95 & 95 \\
\hline P.24R & 680 & 1.570 & 190 & 8,9 & 8,3 & 4,0 & 99 & 92 & 94 \\
\hline P.25 & 1.120 & 5.670 & 470 & 14,7 & 30,0 & 9,9 & 98 & 92 & 94 \\
\hline Total & $\mathbf{7 . 6 4 0}$ & $\mathbf{1 8 . 8 8 0}$ & $\mathbf{4 . 7 4 0}$ & 100 & 100 & 100 & & & 92 \\
\hline
\end{tabular}

posição das espigas às condições adversas de clima que aumentam a probabilidade de ataques de insetos e a incidência de doenças. Na seleção das espigas da SCS 154 Fortuna foram descartados muitos exemplares com tamanho pequeno ocasionado pelas limitações do desenvolvimento das plantas no campo, que posteriormente foram comprovadas através de avaliação das condições físicas e químicas do solo da lavoura. A escolha de áreas com alta fertilidade de solo, sem problemas de compactação e a aplicação de fertilizantes visando atingir altas produtividades no campo de produção de sementes devem ser adotados para a correção do problema.

Na Tabela 2 são discriminadas as quantidades de sementes beneficiadas classificadas nas distintas peneiras. As três variedades de milho apresentaram o maior percentual de sementes beneficiadas classificadas na peneira 22 (8mm). Amostras dos lotes beneficiados de sementes de milho foram enviadas ao laboratório para realização do teste de germinação atendendo etapa obrigatória da produção de semente certificada ( $\mathrm{C} 1$ e C2).

Todos os lotes beneficiados atenderam os padrões mínimos exigidos pela legislação vigente (instrução normativa do Mapa 45/2013) para a produção de sementes certificadas ( $\mathrm{C} 1$ ou $\mathrm{C2}$ ) de miIho variedade (BRASIL, 2013). Os lotes de sementes de milho beneficiados pela empresa apresentaram germinação entre $90-99 \%$ (Tabela 2). 0 padrão mínimo de germinação para comercializar sementes certificadas de milho variedade é de $85 \%$ (BRASIL, 2013). Todos os lotes beneficiados apresentaram 100\% de pureza das sementes e no exame de sementes infestadas (danificadas por insetos, nesse caso, o gorgulho-do-milho) menos de $3 \%$ das sementes tratadas das três variedades foram danificadas pelo ataque de gorgulhos. Na variedade SCS 156 Colorado de 1 até $8 \%$ das sementes coletadas na moega e as retidas nas peneiras 20R, 22R, 24R e 22L, antes da passagem na mesa densimétrica, estavam infestadas. Entretanto, após a passagem das sementes pela mesa densimétrica ocorreu a redução do percentual de sementes infestadas e os valores se mantiveram abaixo do limite (3\%). Dessa forma, comprova-se que os processos executados na unidade de beneficiamento foram eficientes na eliminação de materiais indesejáveis e na preservação da integridade física das sementes, mantendo a alta qualidade fisiológica obtida no campo.

\section{Referências}

BRASIL. Ministério da Agricultura, Pecuária e Abastecimento. Instrução Normativa no 45, de 17 de setembro de 2013. Padrões para a produção e a comercialização de sementes. Brasília (DF): Diário Oficial da União, 20 set. 2013.

CARVALHO, N.M.; NAKAGAWA, J. Sementes: ciência, tecnologia e produção. Jaboticabal: FUNEP, 429 p, 2000.

FERREIRA, R.L.; SÁ, M.E. Contribuição de etapas do beneficiamento na qualidade fisiológica de sementes de dois híbridos de milho. Revista Brasileira de Sementes, v.32, p.99-110, 2010.

MARTIN, T.N.; TOMAZELLA, A.L.; CÍCERO, S.M.; NETO, D.D.; FAVARIN, J.L.; VIEIRA JÚNIOR, P.A. Questões relevantes na produção de sementes de milho - primeira parte. Revista da Faculdade de Zootecnia, Veterinária e Agronomia - FZVA, v.14, p.119-138, 2007.

TROGELLO, E.; NOBRE, D.A.C.; KOLLING, E.M.; MODOLO, A.J.; TROGELLO, A.G. Acompanhamento de uma unidade beneficiadora de sementes de milho - estudo de caso. Revista Brasileira de Milho e Sorgo, v.12, p.193-201, 2013. 